\title{
Determining the best procedure for radial artery harvest: Prospective randomized trial for early postharvest complications
}

\author{
Mitsumasa Hata, MD, PhD \\ Motomi Shiono, MD, PhD \\ Akira Sezai, MD, PhD \\ Mitsuru lida, MD \\ Akira Saitoh, MD \\ Tsutomu Hattori, MD \\ Shinji Wakui, MD \\ Masao Soeda, MD \\ Nanao Negishi, MD \\ Yukiyasu Sezai, MD
}

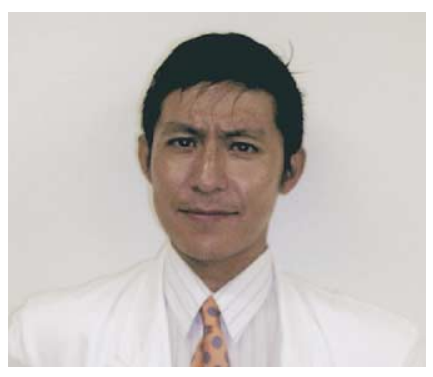

Dr Hata

From the Second Department of Surgery, Nihon University School of Medicine, Tokyo, Japan.

Supported by the Department of Cardiovascular Surgery, Nihon University School of Medicine, Tokyo, Japan.

Received for publication May 18, 2004; revisions received Aug 28, 2004; accepted for publication Sept 3, 2004.

Address for reprints: Mitsumasa Hata, MD, $\mathrm{PhD}$, The Second Department of Surgery, Nihon University School of Medicine, 30-1 Ooyaguchi Kamimachi Itabashi-ku, Tokyo 173-8610, Japan (E-mail: mihata@med. mihon-u.ac.jp).

J Thorac Cardiovasc Surg 2005;129:885-9

$0022-5223 / \$ 30.00$

Copyright (C) 2005 by The American Association for Thoracic Surgery

doi:10.1016/j.jtcvs.2004.09.009
Objective: Although useful procedures for radial artery harvest have been reported, forearm circulation and collateral perfusion after radial artery harvesting remain unknown. To assess an optimal radial artery harvest technique for forearm circulation, we designed a prospective randomized trial.

Methods: Ninety patients were divided into 3 groups of 30 patients. Electrocautery, an ultrasonic scalpel, or sharp scissors and hemoclips were used to harvest radial arteries in groups 1, 2, and 3, respectively. The incidences of harvest site pain, numbness, swelling, discomfort, hematoma, and infection were compared. With forearm thermography, recovery times from cooled down $5^{\circ}$ back to rest temperature were compared between groups. All patients had postoperative forearm angiography at 1 and 12 months.

Results: Although there were no differences in the incidences of pain, swelling, and discomfort, the incidence of numbness was significantly lower in group $3(P=$ $.003)$. The temperature recovery time was significantly shorter in group $3(P=$ .0009). On postoperative angiography at 1 month, the incidence of the development of interosseous arteries was significantly higher in group $3(86.7 \%)$ than in groups $1(23.3 \%)$ and $2(36.7 \%)$. The 12-month study, however, showed that there was no difference among groups $(73.3 \%, 80.0 \%$, and $93.3 \%$ in groups 1,2 , and 3 , respectively).

Conclusions: These results suggest that sharp dissection with scissors and clips may be better for early postharvest forearm circulation and can decrease the incidence of hand numbness. However, there were no differences among the 3 methods with respect to forearm circulation 12 months after radial artery harvest.

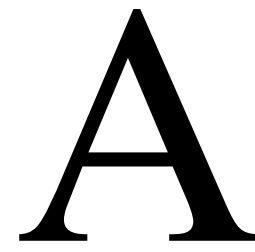

lthough there have been studies evaluating the radial artery (RA) graft free flow and patency in various RA harvest techniques, ${ }^{1,2}$ differences in forearm circulation and collateral perfusion in RA harvest techniques have not been described. We designed a prospective randomized trial to assess the optimal RA harvest technique for maintaining forearm circulation and preventing harvest site complications. 
TABLE 1. The incidence of early postoperative forearm complications

\begin{tabular}{lcccc}
\hline Complication & Group 1 & Group 2 & Group 3 & P value \\
\hline Ischemia & 0 & 0 & 0 & NS \\
Infection & 0 & 0 & 0 & NS \\
Hematoma & $2(6.7 \%)$ & $1(3.3 \%)$ & $1(3.3 \%)$ & NS \\
Pain & 0 & $3(10 \%)$ & $1(3.3 \%)$ & NS \\
Numbness & $6(20 \%)$ & $9(30 \%)$ & 0 & .003 \\
Swelling & $1(3.3 \%)$ & 0 & 0 & NS \\
Discomfort & 0 & 0 & $1(3.3 \%)$ & NS
\end{tabular}

NS, Not significant.

TABLE 2. Results from thermography

\begin{tabular}{|c|c|c|c|c|}
\hline Variable & Group 1 & Group 2 & Group 3 & $P$ value \\
\hline Early RTD $\left({ }^{\circ} \mathrm{C}\right)$ & $1.8 \pm 0.6$ & $0.7 \pm 0.5$ & $0.4 \pm 0.3$ & NS \\
\hline 12-month RTD $\left({ }^{\circ} \mathrm{C}\right)$ & $0.5 \pm 0.4$ & $0.5 \pm 0.3$ & $0.4 \pm 0.2$ & NS \\
\hline Early TRT (s) & $225.1 \pm 62.5$ & $210.5 \pm 54.3$ & $17.4 \pm 11.5$ & .0009 \\
\hline 12-month TRT (s) & $96.1 \pm 32.3$ & $90.5 \pm 44.1$ & $16.7 \pm 9.5$ & NS \\
\hline
\end{tabular}

$R T D$, Rest temperature difference; $T R T$, temperature recovery time; $N S$, not significant.

\section{Patients and Methods}

Ninety patients were enrolled in this trial. Entry criteria were that the patient had an indication for coronary artery bypass grafting with a negative finding on a modified Allen test; patients with uncontrolled diabetes, peripheral vascular disease, severe obesity (body mass index of $>35 \mathrm{~kg} / \mathrm{m}^{2}$ ), renal dysfunction (serum creatinine level of $>2.0 \mathrm{mg} / \mathrm{dL}$ ), poor left ventricular function (ejection fraction of $<35 \%$ ), off-pump coronary artery bypass grafting, or emergency operations were also excluded. All patients gave written informed consent to take part in this trial.

\section{Harvesting Techniques}

We randomized patients into 3 categories. In group 1, RAs were harvested by electrocautery; in group 2, by ultrasonic scalpel; and in group 3, by sharp scissors and hemoclips. All RAs were mobilized by the same operator (M.H.). In group 1 , all the branches of RA were exposed by the electrocautery. Hemoclips were put on just the proximal side of the big branches. Otherwise, the electrocautery was used to cut the branches. The RA was removed together with its collateral veins after its proximal and distal ends were compressed. In group 2, all the branches were cut with the surrounding tissue by an ultrasonic scalpel without exposure of any branches, and the RA was then removed by the same technique as in group 1. In group 3, all branches were exposed by sharp scissors. After the proximal and distal sides of all branches were clipped, the RA was removed, together with its collateral veins.

We assessed postharvest forearm perception by using a questionnaire that contained 4 statements regarding pain, numbness, swelling, and discomfort. The available re- sponses were just "yes" or "no." The questionnaire was administered at 7 days and 12 months after surgery. By using forearm thermography, which is a testing technique that uses infrared light and can take an accurate measurement of body-surface temperature without direct contact, the differences in rest temperatures between the surgical and nonsurgical forearms were compared among groups. Also, temperature recovery times, from cooled down by $5^{\circ}$ with an ice pack back to the normal rest temperature of the surgical site, were also compared. All examinations were made at 7 days and 12 months after surgery. All patients had graft and forearm angiography at 1 and 12 months after surgery.

\section{Statistical Analysis}

Statistical calculations were performed with StatView (SAS Inc, Cary, NC) on a personal computer. Results are expressed as mean \pm SD. Statistical differences between groups were analyzed with $\chi^{2}$ testing and analysis of variance.

\section{Results}

Incidences of early postoperative forearm and hand problems are shown in Table 1. There were no complications of post-RA harvest hand ischemia with hand pain on exertion, Raynaud syndrome, or wound infection. Although there were no differences in the incidences of pain, swelling, or discomfort, the incidence of numbness was significantly lower in group $3(P=.003)$. These symptoms disappeared in all patients by the postoperative 12-month survey.

On postoperative day 7, although there was no difference in terms of rest temperature between the harvest and non- 


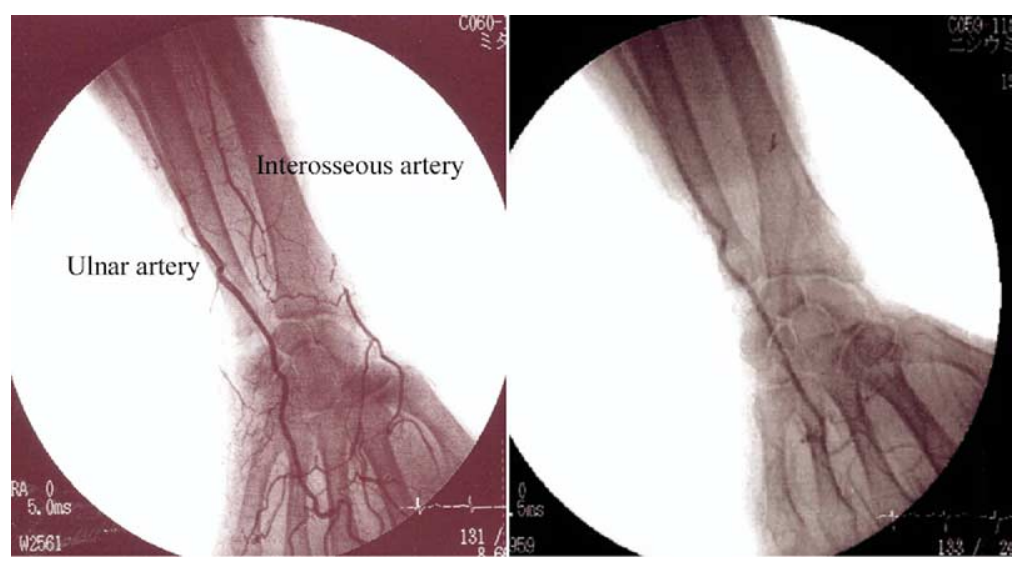

Figure 1. Early forearm angiography. In group 3, the interosseous arteries were well developed and connected to the palmar arch (left). In group 1 or 2 , the collateral vessels from the interosseous arteries were not so well developed or connected to the palmar arch (right).

harvest forearm $\left(1.8^{\circ} \pm 0.6^{\circ}, 0.7^{\circ} \pm 0.5^{\circ}\right.$, and $0.4^{\circ} \pm 0.3^{\circ}$ in groups 1,2 , and 3 , respectively), the temperature recovery time was significantly shorter in group $3(225.1 \pm 62.5$ seconds, $210.5 \pm 54.3$ seconds, and $17.4 \pm 11.5$ seconds in groups 1,2 , and 3 , respectively; $P=.0009$; Table 2 ). The 12-month study, however, showed that there were no differences in terms of rest temperature difference $(0.5 \pm 0.4$ seconds, $0.5 \pm 0.3$ seconds, and $0.4 \pm 0.2$ seconds in groups 1,2 , and 3 , respectively) or temperature recovery time $(96.1 \pm 32.3$ seconds, $90.5 \pm 44.1$ seconds, and 16.7 \pm 9.5 seconds in groups 1,2 , and 3 , respectively; Table 2). Postoperative 1-month forearm angiography showed that in 26 patients $(86.7 \%)$ in group 3, the interosseous arteries were well developed and connected to the palmar arch (Figure 1). However, in groups 1 and 2, this finding was indicated in just $7(23.3 \%)$ and 11 patients $(36.7 \%)$, respectively. In other patients, collateral vessels from interosseous arteries were not so well developed or connected to the palmar arch (Figure 1). Although at postoperative 1-month angiography the prevalence of this finding was significantly higher in group $3(P=.0012)$, there was no difference among groups in the 12 -month study $(73.3 \%, 80.0 \%$, and $93.3 \%$ in groups 1,2 , and 3 , respectively).

\section{Discussion}

We found several significant symptoms in post-RA-harvested hands. Particularly, in groups 1 and 2, the incidences of hand pain and numbness were somewhat high. Tatoulis and colleagues ${ }^{3}$ reported that post-RA harvest scar complaints were indicated in $33 \%$ of patients at 3 months after surgery. Royse and colleagues ${ }^{4}$ reported the prevalence of scar tenderness or hypersensitivity to be $20 \%$. In fact, they used electrocautery for their RA harvesting. These numbers are quite similar to ours in group 1, in which an electrocautery was used to harvest RAs. Conversely, Budillon and colleagues $^{5}$ used only sharp scissors and metal clips for RA harvesting and reported that post-RA harvest cutaneous paresthesia was indicated in just $3.7 \%$ of the patients. Similarly, in group 3 in our trial, post-RA harvest forearm complications occurred in just $0 \%$ to $3.3 \%$ of patients. What, then, is the cause of the differences between groups?

In general, post-RA harvest hand pain and numbness are considered to be due to surgical trauma of the superficial branch of the radial or lateral cutaneous nerves. ${ }^{6}$ A low incidence of nerve damage would indicate that all nerves but the lateral cutaneous nerve of the forearm have been easily avoided. In all procedures in this study, care was taken to avoid the lateral cutaneous nerve, which crosses the RA laterally to medially near the distal extremity of the incision. Saeed and colleagues ${ }^{7}$ reported that the occurrence of sensory symptoms is due to often-unavoidable trauma or edema around the superficial branch of the radial or the lateral cutaneous nerves of the forearm. Obviously, electrocautery may deteriorate tissue around the RA and cause more edema because of thermal injury. Even with the ultrasonic scalpel procedure, tissue edema may be caused after RA harvest because of ultrasonic vibration and tissue protein denaturation. The ultrasonic scalpel is a surgical instrument for cutting and coagulating tissues; it operates at a frequency of $55.5 \mathrm{kHz}$. Its coagulation and cutting mechanisms are different from those of electrocautery. Bleeding vessels are coapted by tamponading and are then sealed with a denatured protein coagulum. Tanemoto and colleagues ${ }^{8}$ reported that an ultrasonic scalpel could limit the thermal effect on the operating site but that the local temperature would still come up to $80^{\circ}$. However, RA harvest with sharp scissors and clips does not cause thermal injury and so can result in minimal tissue damage.

In thermography in this study, although there was no significant difference regarding the rest temperatures of the 
harvest forearms, the temperature recovery time was significantly shorter in the harvest sites undergoing the sharpscissors procedure. We consider that the sharp-scissors procedure can reduce collateral damage compared with ultrasonic scalpel electrocautery, thus allowing the surgeon to dissect closer to the RA and reducing thermal injury around the muscle. Most muscles of the forearm are predominantly-directly or indirectly — supplied by the ulnar artery rather than the RA. Furthermore, collateral blood from the ulnar artery provides the main blood supply to the ulnar and median nerves, with important sensory and motor functions. ${ }^{4}$ These findings are considered to well represent our patients' perceptions in the early postharvest forearm assessments.

There are still concerns that RA removal may effectively reduce forearm blood supply. Several investigators have reported on collateral blood flow in post-RA harvest forearms by using a duplex scan or plethysmography. ${ }^{9-11}$ However, there have been no reports of direct angiographic assessment of post-RA harvest forearm collateral blood flow. The vascular supply to the forearm is provided by an anastomotic network that receives contributing branches from the RA, the ulnar artery, and the anterior and posterior interosseous arteries. Buxton's group at Melbourne University reported that even though the superficial palmar branch of the ulnar artery did not supply the thumb in approximately $34 \%$ of hands, a complete deep palmar arch was present in all hands, thereby enabling the RA to be safely harvested. ${ }^{12}$ Most important is the protection of the small collateral vessels from the ulnar and interosseous arteries. In Buxton's unit, they use only a sharp-scissors technique to prevent thermal injury of collateral vessels around the tissue and so could state that RAs could be safely removed in all hands. ${ }^{13}$ Rafael Sadaba and colleagues ${ }^{14}$ reported that removal of the RA significantly reduced tissue perfusion in the hand and forearm but did not affect hand function in the short term in their study with technetium Tc $99 \mathrm{~m}$. They did not describe details of their harvest technique but did mention a standardized manner with a combination of electrocautery and sharp scissors. In this study, early post-RA harvest forearm angiography showed well-developed collateral perfusion from the interosseous artery connecting directly to the distal side of the RA in patients in whom the sharp-scissors technique was used. There were no such findings in the early stage for the other 2 methods. This might suggest that the small collateral vessels were damaged by thermal injury with the electrocautery or ultrasonic scalpel.

Numbness and paresthesia are the most common complaints in post-RA harvest forearms, but usually these symptoms are transient, without any functional disturbance. ${ }^{6}$ Meharwal and Trehan ${ }^{15}$ reported that such symptoms disappeared between 3 and 6 months in 98.8\% of patients. Another study using questionnaires also noted that
$98.1 \%$ of patients had no problems with their hands at 12 months after surgery. ${ }^{16}$ There was no incidence of postharvest hand pain in any patient in this study, and numbness was gone by the 12-month survey. Even in groups 1 and 2, rest temperature and temperature recovery time on thermography markedly improved. Furthermore, forearm angiograms showed that the collateral vessels from the interosseous and ulnar arteries had developed at 12 months after surgery. Such findings would be related to recovery from any transient thermal injury of the nerves and inflammatory edema of the tissue around the RA harvest site. This would have been caused by recovery of the collateral blood flow from the anastomotic network in the forearm. We believe that meticulous dissection using only sharp scissors and clips is critical for avoiding early postoperative neurologic sequelae of RA harvesting. However, any consequent injury after surgery by electrocautery or the use of an ultrasonic scalpel may be transient and will improve in the long term.

\section{Conclusions}

RA harvesting with sharp scissors and clips seems much better for early postharvest forearm circulation and can decrease the incidence of hand numbness. However, there were no differences in forearm circulation among the different harvest methods at 12 months after RA harvesting. From a patient's long-term postoperative perspective, any RA-harvesting techniques would be acceptable.

\section{References}

1. Isomura T, Suma H, Sato T, Horii T. Use of Harmonic Scalpel for harvesting arterial conduits in coronary artery bypass. Eur J Cardiothorac Surg. 1998;14:101-3.

2. Galajida Z, Peterffy A. Minimally invasive harvesting of the radial artery as a coronary artery bypass graft. Ann Thorac Surg. 2001;72:291-3.

3. Tatoulis J, Buxton BF, Fuller JA. Bilateral radial artery grafts in coronary reconstruction: technique and early results in 261 patients. Ann Thorac Surg. 1998;66:714-20.

4. Royse AG, Royse CF, Shah P, Williams A, Kaushik S, Tatoulis J. Radial artery harvest technique, use and functional outcome. Eur J Cardiothorac Surg. 1999;15:186-93.

5. Budillon AM, Nicolini F, Agostinelli A, Beghi C, Pavesi G, Fragnito $\mathrm{C}$, et al. Complications after radial artery harvesting for coronary artery grafting: our experience. Surgery. 2003;133:283-7.

6. Acar C, Jebara VA, Portoghese M, Beyssen B, Pagny JY, Grare P, et al. Revival of the radial artery for coronary artery bypass grafting. Ann Thorac Surg. 1992;54:652-60.

7. Saeed I, Anyanwu AC, Yacoub MH, Amrani M. Subjective patient outcome following coronary artery bypass surgery using the radial artery: results of a cross-sectional survey of harvest site complications and quality of life. Eur J Cardiothorac Surg. 2001;20:1142-6.

8. Tanemoto K, Kanaoka Y, Murakami T, Kuroki K. Harmonic scalpel in coronary artery bypass surgery. J Cardiovasc Surg. 1998;39:493-5.

9. Ronan JW, Perry LA, Barner HB, Sundt TM III. Radial artery harvest: comparison of ultrasonic dissection with standard techniques. Ann Thorac Surg. 2000;69:113-4.

10. Chong WCF, Ong PJL, Hayward CS, Collins P, Moat NE. Effect of radial artery harvesting on forearm function and blood flow. Ann Thorac Surg. 2003;75:1171-4.

11. Brodman RF, Hirsh LE, Frame R. Effect of radial artery harvest on collateral forearm blood flow and digital perfusion. $J$ Thorac Cardiovasc Surg. 2002;123:512-6. 
12. Ruengsakulrach P, Eizenberg N, Fahrer C, Fahrer M, Buxton BF. Surgical implications of variations in hand collateral circulation: anatomy revisited. J Thorac Cardiovasc Surg. 2001;122:682-6.

13. Hata M, Seevanayagam S, Manson N, Rosalion A, Matalanis G, Raman J, et al. Radial artery 2000-risk analysis of mortality for coronary bypass surgery with radial artery. Ann Thorac Cardiovasc Surg. 2002;8:354-7.

14. Rafael Sadaba J, Conroy JL, Burniston M, Maughan M, Munsch C.
Effect of radial artery harvesting on tissue perfusion and function of the hand. Cardiovasc Surg. 2001;9:378-82.

15. Meharwal ZS, Trehan N. Functional status of the hand after radial artery harvesting: results in 3977 cases. Ann Thorac Surg. 2001;72: 1557-61.

16. Hata M, Raman J, Seevanayagam S, Hare D, Buxton B. Post radial artery harvest hand perception-postoperative 12-month follow-up results. Circ J. 2002;66:816-8.

\section{Availability of Journal back issues}

As a service to our subscribers, copies of back issues of The Journal of Thoracic and Cardiovascular Surgery for the preceding 5 years are maintained and are available for purchase from Elsevier Inc. until inventory is depleted. Please write to Elsevier Inc., Subscription Customer Service, 6277 Sea Harbor Dr, Orlando, FL 32877 , or call $800-654-2452$ or $407-345-4000$ for information on availability of particular issues and prices. 